- Process 4-1: Isobaric heat extraction in the evaporator

\section{B. Nanoparticles:}

Nanoparticles as well as Nano fluids have grabbed attention of many in this present scenario. Nanoparticles are nanometer sized particles in the order of 10-9 m. Nano fluids are engineered colloids which consist of a base fluid with Nano sized particles $(1-100 \mathrm{~nm})$ suspended within them.Nanofluids have special advantage that these fluids possess enhanced properties than the base fluids. They possess many attractive features like enhances thermo physical properties, higher thermal conductivity and higher surface area. There are several classifications of Nano fluids in which the nanoparticles dispersed in the base fluids may be of metal oxides, carbides, nitrides, carbon nanotubes, diamond, graphite etc.

\section{LITERATURE CONSIDERING THERMOPHYSICAL PROPERTIES. \\ REVIEW}

More than a century ago, Maxwell et al. initiated the efforts to enhance inherently poor thermal conductivity of liquids by adding solid particles in base fluids. Earlier studies used millimetre or micrometre solid particles, which led to problems such as rapid settling of solid particles, clogging, surface abrasion \& high-pressure drop, limiting their practical applications. Nano fluids have good potential to overcome these problems. Choi (1995) et al. conceived the novel concept of Nano fluids by making use of particles sizes in the order of 1 to 100 $\mathrm{nm}$. Research on heat transfer enhancement by adding nanoparticles has had mixed results since then. Gains $\&$ losses of heat transfer have been reported. Main factors, which influence the results, are nanoparticle material, nanoparticle concentration, Nano fluid preparation methods \& testing consistency. In last decade, the number of published articles mentioning nanoparticles has increased significantly in refrigeration field.

Amy Majgaonkar (2016) et al. reviewed in his article that in refrigeration systems, Nano lubricant improves tribological characteristics improving compressor performance; Nano refrigerant improves thermophysical properties, improving refrigerating effect. Presence of nanoparticles enhances solubility between oil \& refrigerant and returns more oil back to the compressor. He has also enclosed that in refrigeration systems, preparation of Nano lubricant is comparatively easier than direct preparation of Nano refrigerant, as only few refrigerants are available in liquid state at atmospheric pressure. Nanoparticles of required type \& size are dispersed in base fluid after precise weighing on electronic balance. Stirring is done in a mechanical stirrer for some period followed by ultra-sonic vibration technique to form a stable Nano fluid. Surface-active agents and/or dispersants are generally not used. Nanoparticles increase the surface area; improve mixing, turbulence \& temperature distribution in Nano fluids. Suspension of highly thermally conductive materials is not always effective to improve the thermal transport properties of Nano fluids. CNT has highest thermal conductivity. Aligned CNTs are easier to disperse. However it is most expensive option. Natural Diamond has second highest thermal conductivity with no significant health risks but is second most expensive option. $\mathrm{CuO}$ $\& \mathrm{ZnO}$ can be dangerous for health. $\mathrm{Al}_{2} \mathrm{O}_{3}$ reacts with water \& heat is generated. Oil has low thermal conductivity whereas refrigerant has very low thermal conductivity. For other nanoparticles study is limited.

Anoop.k (2014) et al. experimented with the mixture of mineral oil and $20 \mathrm{~nm}$ silicon dioxide $\left(\mathrm{SiO}_{2}\right)$ and of 1, 2 Nano Particle Volume Fraction in Lubricant and resulted more about the viscosity of the mixture. He stated that viscosity is directly proportional to Nano Particle Concentration as well as pressure. He also concluded that at high temperature viscosity of the Nano lubricant is less affected by pressure. Also viscosity is inversely proportional to temperature and below $100^{\circ} \mathrm{C}$ viscosity remains almost same [1] When the temperature and the pressure is very high the viscosity of the Nano fluid is unexpectedly affected. While mentioning about viscosity Dhindsa.G (2013) et al, reported that viscosity increases linearly with respect to Nano Particle Volume Fraction up to 0.03 then it increases sharply. Also he stated that small values of Nano Particle Volume Fraction are useful for refrigeration setups upon using $\mathrm{Al}_{2} \mathrm{O}_{3}$ of 20 $\mathrm{nm}$ mixed with R11 refrigerant of Nano Particle Volume Fraction 0.01 to 0.05 [2]. Similarly Peng.H (2011) et al. used 20, 50, $80 \mathrm{~nm}$ of $\mathrm{Cu}, 20 \mathrm{~nm}$ of $\mathrm{Al}$ and $40 \mathrm{~nm}$ of $\mathrm{CuO}$ mixed with R133, R141b, nPentane and Oil for his research to study the effect on Nano Particle density, Nano Particle size, Dynamic viscosity and Nano Lubricant Mass Fraction in accordance with the migration ratio and concluded that Migration Ratio is inversely proportional to all the above factors [3]. Bartelt.K (2008) et al. 
concluded that at $4 \%$ of Nano Particle Volume Fraction in Lubricant, flow boiling experiment showed $0.5 \%$ Nano Lubricant Mass Fraction has no effect on flow Heat Transfer Co-Efficient. Also on $1 \%$ of Nano Lubricant Mass Fraction increases Heat Transfer Co-Efficient from $42 \%$ to $84 \%$. When NLMF is increased to $2 \%$ Heat Transfer Co-Efficient increases to 50 to $101 \%$. But presence of Nano Particle has a very poor effect on systems pressure drop [4]. At 1.5 Nano Particles Mass Fraction In Lubricant and 1 Nano Lubricant Mass Fraction In Refrigerant, Heat Transfer Co-Efficient increases to $83 \%$ when compared to pure refrigerant was achieved by Behabadi et al (2015) [5]. Ding.G et al (2009) used the mixture of $\mathrm{CuO}$ and $\mathrm{RB} 68 \mathrm{EP}$ and $\mathrm{R} 113$ refrigerant of $40 \mathrm{~nm}$. He concluded that the migrated mass of the $\mathrm{NP}$ in pool boiling increases with increase in the initial mass of the nano refrigerant. Aslo Mirgration ratio is inversely proportional to the Nano Particle Volume Fraction [6]. But contrarily to some of the research works Fedele.L et al (2010) achieved no improvement in rotary compressor efficiency or heat transfer [7] when using $\mathrm{TiO}_{2}$ with $\mathrm{R} 134 \mathrm{a}$ mixed with POE as well as Mineral Oil. Hadi et al (2011) brought out through his study with $\mathrm{CuO}$ of particle size ranging from $15-70 \mathrm{~nm}$ and 0.1 to 1 Nano Particles Mass Fraction In Lubricant as a mixture when mixed with R134a and oil that for all the heat flux values evaporating Heat Transfer Co-Efficient increases when varying Nano Particle Concentration from 0.1 to $0.55 \%$ and then it gradually decreases. Also when NP is varied from 15 to $25 \mathrm{~nm}$ it increases and then it slowly decreases [8]. Some of the studies says that Nano fluid preparation method affects resultant thermal conductivity. NP size in dry state may be different than in effective NP size in Nano fluid. This is to be remembered while matching with the theory. Also flow boiling Heat Transfer Co-Efficient increases with increase in Nano Particle Concentration. Increase in Heat Transfer Co-Efficient up to $100 \%$ compared with bare refrigerant and Polyester oil. Excellent dispersion of $\mathrm{CuO}$ NP with $\mathrm{R} 134 \mathrm{a}$ and POE oil is having insignificant effect on the flow pressure drop [9]. Also dispersion results influences the flow boiling Heat Transfer Co-Efficient was achieved by Henderson et al (2010) when $\mathrm{SiO}_{2}$ Nano particles were used [10].

Jiang.W et al (2009) used several nanoparticles and mixed it with R113 refrigerant and ended up that thermal conductivity decreases with increase in NPVF. Also thermal conductivities of the Nano particles with various kinds of NPs is close to one another if the NPVF are same [11]. In some cases the nucleate pool boiling Heat Transfer Co-Efficient has increased drastically from $50 \%$ to $275 \%$ [12] but when Nano Particle Volume Fraction In Lubricant is increased it imparts negative impact on the Heat Transfer Co-Efficient [13] but achieved better lubrication properties and better polishing of friction plates than pure oil. Some other studies has been conducted to check the relationship between thermal conductivities and amount of nanoparticles. Mahbubul et al (2013) resulted that thermal conductivity is direstly proportional to NPVF, Temperature, Pressure drop, Pumping power and Viscosity but inversely proportional to the particle size[14]. When heat fluxes less than $30 \mathrm{~kW} / \mathrm{m}^{2}$ is used about $36.6 \%$ Pool boiling Heat Transfer Co-Efficient has been increased [15]. Peng et al (2009) used $\mathrm{CuO}$ and R113 mixture and obtained about $29.7 \%$ rise in their flow boiling Heat Transfer Co-Efficient rather than using bare refrigerants [16]. His research also included some other results viz., nucleate pool boiling Heat Transfer Co-Efficient was increased by $63.4 \%$. the enhancement increases with the increase of Nano Particle Concentration in the nanoparticles or oil suspension and decreases with increase in nanoparticle/oil suspension concentration. He proposed useful heat transfer correlation [17]. He also resulted that nucleate pool boiling Heat Transfer CoEfficient increased up to maximum of $23.8 \%$ with decrease in nanoparticles size at the fixed Nano Particle Concentration. The enhancement increases with increase in the Nano Particle Concentration in the mixture and increases with the decrease of mixture concentration while using $\mathrm{Cu}$ of various Nano Particle Concentration in Refrigerant and Nano lubricant Mixture ranging from 0.1 to 1.0 and R113 refrigerant [18]. Nucleate pool boiling Heat Transfer CoEfficient decreases with increase in Nano Particle Concentration at high heat flux. At higher Nano Particle Concentration the effect of pressure on the boiling Heat Transfer Co-Efficient is less than that at lower Nano Particle Concentration [19]. Also Wu.X et al (2008) found that pool boiling Heat Transfer CoEfficient increases with low Nano Particle Concentration and decreases with high Nano Particle Concentration [20]. Some researches shows that by increasing the Nano Particle Concentration, wetting of the surface gets higher. Also surface roughness increases with increase in Nano Particle Concentration [21]. 
International Journal of Trend in Scientific Research and Development (IJTSRD) ISSN: 2456-6470

\section{LITERATURE REVIEW CONSIDERING APPLIED RESEARCHES AND APPLICATIONS:}

All the above mentioned research studies were performed to find out the thermophysical properties and their relationship with the incorporation of nanoparticles in the system. The following deals with the brief summary of the applied research in the refrigeration systems. Abbas.M et al (2013) improved the Co-Efficient Of Performance of the refrigeration of the system by $4.2 \%$ at $0.1 \%$ of amount of CNT. Various researches has been done using various nanoparticles and the results were dealt in comparison with the properties of the particles [22]. Bi.S et al (2011) used $\mathrm{TiO}_{2}$ of $50 \mathrm{~nm}$ and Nano Particle Concentration of 0.1 and $0.5 \mathrm{~g} / \mathrm{L}$ along with R600a refrigerant and achieved reduced energy consumption and improved freezing capacity when compared with pure R600a [23] . Also earlier $\mathrm{Al}_{2} \mathrm{O}_{3}$ of 0.01 Nano Particles Mass Fraction In Lubricant to 0.1 Nano Particles Mass Fraction In Lubricant resulted in more than $20 \%$ reduced energy consumption and increased freezing capacity. He also stated that 5 to $10 \%$ of energy has been additionally saved. Oil return was also improved in this case [24]. Nanoparticles has he great advantage of reducing power consumed by the compressor and increases the Co-Efficient $\mathrm{Of}$ Performance of the refrigerants [25]. When blending $\mathrm{Al}_{2} \mathrm{O}_{3}$ with hydrocarbon refrigerant to the lubricant effectively reduced power consumption. Kumar.D et al (2012) [26] used $\mathrm{Al}_{2} \mathrm{O}_{3}$ as well as used $\mathrm{ZnO}$ (2014) [27] deceived that the performance of the refrigeration system improved with reduction in energy consumed by the compressor. Sajumon.K et al (2013) found through his study that nanolubricants shows higher viscosity and smaller friction co-efficient. It also result in the less power consumptions with high heat transfer rates and Co-Efficient Of Performance [28]. Some many researches has been explicitly done by varying nanoparticles and presented them to the world [29] , [30] , [31]. Researches has also been done for air-conditioning systems. Air conditioning system with $\mathrm{CuO}$ nanorefrigerant is found to be more energy efficient than $\mathrm{Al}_{2} \mathrm{O}_{3}$ nano refrigerants [32]. Nanoparticles also improve antiwear, friction conditions and increase the cooling capacity and CoEfficient Of Performance of the setup [33].

In many studies, where nanoparticles are directly mixed with refrigerants following terminology shall be useful NPMFR = Nanoparticle mass fraction in refrigerant $=$ Ratio of mass of NP to mass of NP- refrigerant mixture. In many studies Nano lubricant is first prepared by mixing nanoparticles with lubricant. Nanolubricant is then mixed with pure refrigerant, thereby making Nano refrigerant. In such cases following terminology \& equations shall be useful.

- $\mathrm{NPMFL}=$ Nanoparticle mass fraction in lubricant $=$ Ratio of mass of NP to mass of NP-lubricant mixture.

- $\mathrm{NPMFL}=\mathrm{wn}=\mathrm{mn} /(\mathrm{mn}+\mathrm{mo})$, where $\mathrm{mn}$ is mass of nanoparticles in $\mathrm{Kg}$, mo is mass of lubricant in Kg.

- NLMFR = Nanolubricant mass fraction in refrigerant $=$ Ratio of mass of Nanolubicants to mass of Nano lubricant and refrigerant mixture $=$ $\mathrm{Xn}, \mathrm{o}=\mathrm{mn}, \mathrm{o} /(\mathrm{mn}, \mathrm{o}+\mathrm{mr})$, where $\mathrm{mn}, \mathrm{o}$ is mass of Nano lubricant in $\mathrm{Kg}, \mathrm{mr}$ is refrigerant mass in $\mathrm{Kg}$.

- $\mathrm{NCRL}=$ Nanoparticle concentration in refrigerant $\&$ nanolubricants mixture $=\mathrm{yn}=\mathrm{wn} \times \mathrm{Xn}, \mathrm{o}$. In cases where volume of lubricant \& nanoparticles is considered while preparing Nano lubricant following terminology shall be useful

- NPVFL = Nanoparticles volume fraction in lubricant $=$ Ratio of volume of NP to volume of NP-lubricant mixture.

\section{CONCLUSION\& FUTURE RESEARCH DIRECTIONS:}

Nano fluids are prepared by dispersing nanoparticles in base fluid. Dispersion stability affects thermophysical properties of Nano fluids. Dispersions can remain stable for some amount of time without coagulation, clustering \& deposition. Many researchers have done the experiments within this stability time \& produced the results. In real life, the refrigeration system can be continuously operated or intermittently operated, the pressure \& temperatures of refrigerant change as it passes through different components in system. Therefore, if Nano refrigerant is to be used in actual refrigeration system then it needs to be stable continuously $\&$ in all practical pressure temperature conditions. Nano fluid preparation methods influence its thermo-physical properties. Property like thermal conductivity depends upon sonication time. In many papers, it is not specifically mentioned that the same preparation method \& same sonication time is used for all the cases studied. Therefore the comparison of thermo- 
physical properties with different nanoparticle material, size \& concentrations may not be on the same platform. Similarly thermo-physical property results of one paper cannot be accurately compared with another paper if different Nano fluid preparation methods are used or different sonication time durations are employed. Nanoparticles travel along with refrigerant in refrigeration cycle. In condenser and evaporator of refrigeration systems, the refrigerant changes its phase. Similar to boiling studies, migration characteristics studies in condensation process also needs equal importance.

Peng et al (2011d) \& Ding et al (2009) studied the migration characteristic of nanoparticles in pool boiling experiment. Such studies shall be useful in refrigeration systems with flooded evaporators. However, the effect of compressor suction pulling force also needs to be considered in such studies to make it applicable to real cases. A large amount of study is still needed to investigate the mechanism of migration. To the author's knowledge no study is yet published with application of nanoparticles in refrigeration systems having flooded evaporators. Density of Nano refrigerant needs to be investigated as depth of the pool of boiling refrigerant in a flooded evaporator exerts a liquid pressure on lower part of heat transfer surface. Therefore, saturation temperature at this surface is higher than that in suction line, which is not affected by the liquid pressure. This temperature gradient must be considered when designing the flooded evaporator. Also oil return ports needs to be located on flooded evaporator shell considering miscibility \& relative density of Nano lubricant/refrigerant. Most of the literature reports that only one type of nanoparticle is studied to make a particular type of Nano fluid. To the author's knowledge, a mixture of different types of nanoparticles dispersed in a base fluid to make Nano fluid containing different types of nanoparticles is not published yet. Also many studies also do not publish nanoparticle size in dry \& in suspension states. Refrigeration systems studied are mostly domestic refrigerator, home air conditioners \& refrigeration test rigs employing small scroll \& reciprocating type compressors. Industrial refrigeration systems are not yet studied, which contain screw \& centrifugal compressors, shell \& tube and plate type heat exchangers. Studied systems are mainly with halocarbon or hydrocarbon refrigerants. However natural refrigerants like ammonia are not yet studied. Studied systems are mainly dry expansion type refrigeration systems; flooded refrigeration systems are not yet studied. Most of the basic studies are related to single phase or nucleate pool boiling. More focus also needs to be given on flow boiling with and without lubricants. Most studies focus on thermal conductivity \& viscosity. Basic studies are also required to focus on properties like latent heat, specific heat, density, surface tension, dielectric strength, miscibility, \& solubility. Nanoparticles which improve lubrication to reduce compressor wear \& tear, enhance HTC, \& able to travel in refrigeration system without accumulation or settling needs to be discovered. Data base with large number of investigations needs to be created, for knowing the trends and deciding future research direction. Since this field is in its infancy stage, it is therefore necessary to create a checklist for parameters, which should be used while publishing research. One such checklist is attempted here.

\section{Checklist:}

- Nanoparticle/S

- Size (Dry \& In Fluid)

- Base Fluid (Refrigerant/ Lubricating Oil/ Other)

- Nano Fluid Preparation Method

- Dispersion Stability Duration

- Were The Experimental Tests Performed Within Dispersion Stability Duration (When Dispersion Is Stable)?

- Details (Name, Type, Quantity) Of Surfactants/ Dispersants If Used

- Nano Particles Mass Fraction, Nano Particles Mass Fraction In Refrigerant, Nano Particles Mass Fraction In Lubricant, Nano Lubricant Mass Fraction In Refrigerant, Nano Particle Concentration In Refrigerant And Nano lubricant Mixture, Nano Particle Volume Fraction, Nano Particle Volume Fraction In Lubricant Whichever Is Applicable

- Details of Sonication Time and Dispersion Method Used

\section{- Experimental/Test Conditions.}

To ensure traceability and repeatability nanoparticle make and production technique may also be added in checklist if possible. It is important to understand the physical mechanisms of heat transfer \& flow behaviour of Nano fluids. Many investigators have provided correlations for predicting thermo-physical properties for Nano fluids. However they are suitable only for narrow range with limited use in practical 
applications. Interdisciplinary study approach may help to develop better prediction methods useful for basic research. In application related research, experimental facility must be capable to allow understanding of the effect of change of one variable while keeping all other variables constant. Refrigeration system performance is affected too many variables like evaporating \& condensing pressure temperature, cooling \& chilling medium temperature, their flow rates, speed, fouling, pressure drops, refrigerant \& oil charge, sub cooling/superheating, input electric supply (voltage, current, power factor, and frequency), ambient temperature causing insulation gains/losses.

\section{REFERENCES:}

1. Anoop, K., et al, 2014, Rheology of mineral oil$\mathrm{SiO} 2$ nanofluids at high pressure and high temperatures, International Journal of thermal sciences, 77 p. 108-115.

2. Dhindsa, G., Lalkundan, R., 2013, Experimental investigation of the viscous behavior of $\mathrm{Al} 2 \mathrm{O} 3$ based nanorefrigerant, International Journal on Theoretical \& Applied Engineering Research in Mechanical Engineering vol. 02, iss. 3 p. 143-147.

3. Peng, H., et al, 2011c, Effect of nanoparticles size on nucleate pool boiling heat transfer/ of refrigerant/oil mixture with nanoparticles, International Journal of Heat \& Mass Transfer, 54, p. $1839-1850$.

4. Bartelt, K., et al, 2008, Flow-boiling of $\mathrm{R} 134 \mathrm{a} / \mathrm{POE} / \mathrm{CuO}$ Nanofluids in horizontal tube, International Refrigeration and Air Conditioning Conference, Purdue University, paper 928.

5. Behabadi, M., et al, 2015, Experimental study on heat transfer characteristics of $\mathrm{R} 600 \mathrm{a} / \mathrm{POE} / \mathrm{CuO}$ nanorefrigerant flow condensation, Experimental Thermal \& Fluid Science, 66 p. 46- 52.

6. Ding, G., et al, 2009, The migration characteristics of nanoparticles in pool boiling process of nanorefrigerant \& nanorefrigerant-oil mixture, International Journal of Refrigeration, 32, p. 114123

7. Fedele, L., et al, 2014, Nanofluids applications as nanolubicants in heat pump systems, International
Refrigeration and Air Conditioning Conference, Purdue University, paper 2170.

8. Hadi, et al, 2011, Heat transfer analysis of vapor compression system using Nano CuO-R134a, International conference on advanced materials engineering, IPCSIT, vol. 15, p. 80-84.

9. Hays, A., et al, 2006, The effect of nanoparticle agglomeration on enhanced nanofluidic thermal conductivity, International Refrigeration and Air Conditioning Conference, Purdue University, paper R132

10. Henderson, K., et al., 2010, Flow-boiling heat transfer of R-134a-based nanofluids in a horizontal tube, International Journal of Heat Mass Transfer, 53 (5-6) p. 944-951.

11. Jiang, W., et al, 2009, Experimental and model research on nanorefrigerant thermal conductivity, ASHRAE HVAC\&R Research, vol. 15 no. 3, p. 651-669.

12. Kedzierski M., Gong M., 2007, Effect of $\mathrm{CuO}$ nanolubricant on R134a pool boiling heat transfer with extensive measurement and analysis details, National Institute of Standards and Technology, USA: NISTIR 7336.

13. Kedzierski, M., 2007, Effect of CuO nanoparticles concentration on R134a/lubricant pool boiling heat transfer with extensive analysis, National Institute of Standards and Technology, NISTIR 7450, p. 1-33.

14. Mahbubul, I., et al, 2013, Thermophysical properties and heat transfer performance of Al2O3/R134a nanorefrigerants, International Journal of Heat \& Mass Transfer, 57, p. 100-108.

15. Park, K., Jung, D., 2007, Boling heat transfer enhancement with carbon nanotubes for refrigerants used in building air- conditioning, Energy and Buildings, 39 (9), p.1061-1064.

16. Peng, H., et al, 2009a, Heat transfer characteristics of refrigerant based nanofluid flow boiling inside a horizontal smooth tube, International Journal of Refrigeration, 32, p. 1259-1270. 
17. Peng, H., et al, 2010b, Nucleate pool boiling heat transfer characteristics of refrigerant/oil mixture with diamond nanoparticles, International Journal of Refrigeration, 33, p. 347-358.

18. Peng, H., et al, 2011c, Effect of nanoparticles size on nucleate pool boiling heat transfer of refrigerant/oil mixture with nanoparticles, International Journal of Heat \& Mass Transfer, 54, p. $1839-1850$.

19. Peng, H., et al, 2011d, Influence of refrigerant based nanofluid composition and heating condition on migration of nanoparticles during pool boiling. Part I: Experimental measurement, International Journal of Refrigeration, 34 (2011), p. $1823-1832$.

20. Wu, X., et al, 2008, Investigation of pool boiling heat transfer of $\mathrm{R} 11$ with $\mathrm{TiO} 2$ nanoparticles, Journal of Engineering Thermophysics, 2008;29(1):124-6.

21. Zhang, F., Jacobi, A., 2014, nanoparticle deposition by boiling on Aluminum surfaces to enhance wettability, International $\mathrm{Refrigeration}$ and Air Conditioning Conference, Purdue University, paper 2397.

22. Abbas, M., et al, 2013, Efficient Air-condition unit by using nano-refrigerant, EURECA 2013, p. 87-88.

23. Zhu, Y., et al, 2011, Research on effect of nanomaterials used in rotary compressors, International Refrigeration and Air Conditioning Conference, Purdue University, paper 1165.

24. Bi, S., et al, 2011a, Performance of domestic refrigerator using TiO2-R600a nano-refrigerant as working fluid, Energy Conversion and Management, 52, p. 733-737.

25. Bi, S., et al., 2008b, Application of nanoparticles in domestic refrigerators, Applied Thermal Engineering, 28, p. 1834-1843.

26. Kumar, D., Elansezhian, R., 2012, Experimental study on $\mathrm{Al} 2 \mathrm{O} 3$ - R134a nano refrigerant in refrigeration systems, International Journal of Modern Engineering Research, vol.2, iss. 5, p. 3927-3929.
27. Kumar, D., Elansezhian, R., 2014, ZnO nanorefrigerant in R152a refrigeration systems for energy conservation \& green environment, Front. Mech. Eng., DOI 10.1007/s11465-014-0285-y

28. Sajumon, K., et al 2013, Performance analysis of nanofluid based lubricants, International Journal of Innovative Research in Science, Engineering and Technology, vol. 2, Sp. Iss. 1, p. 832-838.

29. Kotu, T., Kumar, R., 2013, Comparison of heat transfer performance in domestic refrigerator using nanorefrigerants \& double pipe heat exchanger, International Journal of Mechanical \& Industrial Engineering, vol. 3, iss. 2, p. 67-73

30. Subramani, N., Prakash, M., 2011, Experimental studies on vapour compression refrigeration system using nanorefrigerants, International Journal of Engineering, Science and Technology, vol. 3 , no. 9, p. 95-102.

31. Subramani, N., et al, 2013, Performance studies on vapour compression refrigeration system using nanolubricant, International Journal of Innovative Research in Science, Engineering and Technology, vol. 2 , iss. 1, p. 522-530

32. Vandaarkuzhali S., Elansezhian, R., 2015, Performance evaluation of air conditioning system using nanofluids, Australian Journal of basics and applied science, 9(7) p. 1-10.

33. Zhu, Y., et al, 2011, Research on effect of nanomaterials used in rotary compressors, International Refrigeration and Air Conditioning Conference, Purdue University, paper 1165. 